\title{
Ottawa 2020 consensus statements for programmatic assessment 2: Implementation and practice
}

Citation for published version (APA):

Torre, D., Rice, N. E., Ryan, A., Bok, H., Dawson, L. J., Bierer, B., Wilkinson, T. J., Tait, G. R., Laughlin, T., Veerapen, K., Heeneman, S., Freeman, A., \& van der Vleuten, C. (2021). Ottawa 2020 consensus statements for programmatic assessment 2: Implementation and practice. Medical Teacher, 43(10), 11491160. https://doi.org/10.1080/0142159X.2021.1956681

Document status and date:

Published: 03/10/2021

DOI:

10.1080/0142159X.2021.1956681

Document Version:

Publisher's PDF, also known as Version of record

Document license:

Taverne

Please check the document version of this publication:

- A submitted manuscript is the version of the article upon submission and before peer-review. There can be important differences between the submitted version and the official published version of record.

People interested in the research are advised to contact the author for the final version of the publication, or visit the DOI to the publisher's website.

- The final author version and the galley proof are versions of the publication after peer review.

- The final published version features the final layout of the paper including the volume, issue and page numbers.

Link to publication

\footnotetext{
General rights rights.

- You may freely distribute the URL identifying the publication in the public portal. please follow below link for the End User Agreement:

www.umlib.nl/taverne-license

Take down policy

If you believe that this document breaches copyright please contact us at:

repository@maastrichtuniversity.nl

providing details and we will investigate your claim.
}

Copyright and moral rights for the publications made accessible in the public portal are retained by the authors and/or other copyright owners and it is a condition of accessing publications that users recognise and abide by the legal requirements associated with these

- Users may download and print one copy of any publication from the public portal for the purpose of private study or research.

- You may not further distribute the material or use it for any profit-making activity or commercial gain

If the publication is distributed under the terms of Article $25 \mathrm{fa}$ of the Dutch Copyright Act, indicated by the "Taverne" license above, 


\title{
Ottawa 2020 consensus statements for programmatic assessment - 2. Implementation and practice
}

\author{
Dario Torre, Neil E. Rice, Anna Ryan, Harold Bok, Luke J. Dawson, Beth \\ Bierer, Tim J. Wilkinson, Glendon R. Tait, Tom Laughlin, Kiran Veerapen, \\ Sylvia Heeneman, Adrian Freeman \& Cees van der Vleuten
}

To cite this article: Dario Torre, Neil E. Rice, Anna Ryan, Harold Bok, Luke J. Dawson, Beth Bierer, Tim J. Wilkinson, Glendon R. Tait, Tom Laughlin, Kiran Veerapen, Sylvia Heeneman, Adrian Freeman \& Cees van der Vleuten (2021) Ottawa 2020 consensus statements for programmatic assessment -2. Implementation and practice, Medical Teacher, 43:10, 1149-1160, DOI: 10.1080/0142159X.2021.1956681

To link to this article: https://doi.org/10.1080/0142159X.2021.1956681

View supplementary material ¿

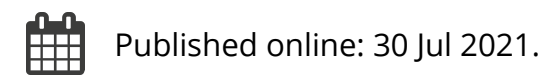

Submit your article to this journal

III Article views: 950

Q View related articles $\sqsubset$

View Crossmark data $\asymp$

Citing articles: 2 View citing articles $₫$ 


\title{
Ottawa 2020 consensus statements for programmatic assessment -2. Implementation and practice
}

\author{
Dario Torre ${ }^{\mathrm{a}}$ (D), Neil E. Rice ${ }^{\mathrm{b}}$ (D), Anna Ryan ${ }^{\mathrm{c}}$, Harold Bok ${ }^{\mathrm{d}}$, Luke J. Dawson $^{\mathrm{e}}$, Beth Bierer ${ }^{\mathrm{f}}$ (D), \\ Tim J. Wilkinson ${ }^{\mathrm{g}}$ (D), Glendon R. Tait ${ }^{\mathrm{h}}$, Tom Laughlin', Kiran Veerapen', Sylvia Heeneman ${ }^{\mathrm{k}}$, Adrian Freeman ${ }^{\mathrm{b}}$ \\ and Cees van der Vleuten ${ }^{\mathrm{k}}$ (iD \\ ${ }^{a}$ Department of Medicine, Uniformed Services University of Health Sciences, Bethesda, MD, USA; ${ }^{b}$ College of Medicine and Health, \\ University of Exeter Medical School, Exeter, UK; 'Department of Medical Education, Melbourne Medical School, University of Melbourne, \\ Melbourne, Australia; ${ }^{d}$ Department of Population Health Sciences, Faculty of Veterinary Medicine, Utrecht University, Utrecht, The \\ Netherlands; 'School of Dentistry, University of Liverpool, Liverpool, UK; ${ }^{f}$ Cleveland Clinic Lerner College of Medicine of Case Western \\ Reserve University, Cleveland, $\mathrm{OH}, \mathrm{USA} ;{ }^{9}$ Education unit, University of Otago, Christchurch, New Zealand; ${ }^{\mathrm{h}} \mathrm{MD}$ Program, Dept. of \\ Psychiatry, and The Wilson Centre, University of Toronto, Toronto, Canada; 'Department of Family Medicine, Dalhousie University, \\ Halifax, Canada; ${ }^{j}$ Faculty of Medicine, University of British Columbia, Vancouver, Canada; ${ }^{k}$ Department of Educational Development and \\ Research, School of Health Profession Education, Maastricht University, Maastricht, The Netherlands
}

\begin{abstract}
Introduction: Programmatic assessment is a longitudinal, developmental approach that fosters and harnesses the learning function of assessment. Yet the implementation, a critical step to translate theory into practice, can be challenging. As part of the Ottawa 2020 consensus statement on programmatic assessment, we sought to provide descriptions of the implementation of the 12 principles of programmatic assessment and to gain insight into enablers and barriers across different institutions and contexts.

Methods: After the 2020 Ottawa conference, we surveyed 15 Health Profession Education programmes from six different countries about the implementation of the 12 principles of programmatic assessment. Survey responses were analysed using a deductive thematic analysis.

Results and Discussion: A wide range of implementations were reported although the principles remained, for the most part, faithful to the original enunciation and rationale. Enablers included strong leadership support, ongoing faculty development, providing students with clear expectations about assessment, simultaneous curriculum renewal and organisational commitment to change. Most barriers were related to the need for a paradigm shift in the culture of assessment. Descriptions of implementations in relation to the theoretical principles, across multiple educational contexts, coupled with explanations of enablers and barriers, provided new insights and a clearer understanding of the strategic and operational considerations in the implementation of programmatic assessment. Future research is needed to further explore how contextual and cultural factors affect implementation.
\end{abstract}

\section{KEYWORDS}

Assessment; feedback; theory; general; portfolio

\section{Introduction}

At the 2020 Ottawa conference, consensus was reached on twelve theoretical principles of programmatic assessment (Heeneman et al. 2021). The consensus group, recognising the challenges of implementation (Norcini and Burch 2007; Norcini et al. 2018), identified that, in order for programmatic assessment and its principles to exert their educational benefits, it is important to share a common understanding of how these principles are implemented across different contexts and regulatory settings. As a follow up to the Ottawa 2020 consensus statement, it was therefore agreed to collect descriptions of implementations of programmatic assessment in order to identify enablers and barriers and to gain insight into those aspects that have been more readily implemented than others.

Programmatic assessment is a longitudinal, developmental approach that fosters and harnesses the learning function of assessment, using a mix of assessment methods for the purpose of providing feedback to learners and informing credible assessment decisions (Schuwirth and Van der

\section{Practice points}

- The descriptions of programmatic assessment implementations contribute to enhance our knowledge and understanding of how the principles of programmatic assessment were applied across different programmes in undergraduate and postgraduate health professions programmes.

- There was a range of implementations tailored and adapted to meet the needs of the local context.

- An individual and organisational shift from a traditional assessment paradigm is critical for a successful implementation of programmatic assessment.

- Implementation of programmatic assessment takes time, needs strong leadership and an equal buy-in from both teachers and learners.

- Implementing programmatic assessment provides insight into curriculum development, enhances feedback literacy and the agency of the learner, and improves the data available for decision making. 
Vleuten 2011; Van Der Vleuten et al. 2012). It has been suggested that a programmatic assessment system may be more effective and valid for discerning true educational progress and performance (Cook et al. 2015). The validity of programmatic assessment has previously been appraised by mapping the overarching structure of Kane's validity theory to the components and tenets of programmatic assessment (Schuwirth and van der Vleuten 2012). Furthermore, there is an increasing body of evidence about the educational benefits and theoretical tenets of programmatic assessment (Van Der Vleuten and Schuwirth 2005; Bierer et al. 2015; Heeneman et al. 2015; Schut et al. 2021).

There are, however, inherent issues with change in any established educational system. The notion that context is likely to affect change and explain any differences in implementations has been described (Damschroder et al. 2009). Political, economic and social context, organisational culture, leadership engagement, characteristics of individuals including stakeholder's acceptance, ability and willingness to embrace change (Wilson and Sloane 2000; Damschroder et al. 2009) may all hinder or facilitate progress and affect change.

Globally, several programmes of education have successfully innovated with programmatic assessment to varying extents (Dannefer and Henson 2007; Freeman and Ricketts 2010; Driessen et al. 2012; Schut et al. 2018; De Jong et al. 2019; Sherbino et al. 2020). Nevertheless, there is limited understanding of implementation approaches taken across different contexts. Health Professions Education programmes involve complex, dynamic, multilevel systems incorporating a number of interacting factors that ultimately affect implementation. Learning how programmatic assessment has been implemented and incorporated in different educational contexts is essential to gain insight on how the stated principles have been translated into educational practices, whilst identifying potential enablers and barriers that may impact implementation processes. These insights can be valuable for educators and institutions that currently use programmatic assessment and for those who are planning to implement it.

In this paper we report on descriptions of implementation of programmatic assessment and how different descriptions align with and adhere to the principles established in the consensus statement. The purpose of this paper is twofold: first to provide descriptions of the implementation components associated with each of the 12 principles identified in phase 1 , capturing the potential variability of implementation strategies across different institutions and educational settings; second, to gain insight into enablers and barriers related to the implementation of programmatic assessment.

\section{Methods}

\section{Participants and data collection}

A sample of 15 programmes from Healthcare Professions Education that had implemented aspects of programmatic assessment was identified by two of the authors (CVD, AF). The sample included undergraduate and postgraduate programmes from six different countries across three continents. Following the Ottawa 2020 conference, the participants in the group who achieved consensus on the
12 principles of programmatic assessment (Heeneman et al. 2021), plus one additional programme, were invited to complete a 16-item questionnaire about implementation of programmatic assessment.

The survey was a semi-structured questionnaire distributed to participants as a Google form comprised of openended questions. Participants were asked to describe how they implemented each of the twelve principles of programmatic assessment in their own programmes, providing, where possible, specific examples. In addition, participants were asked about enablers, barriers encountered, lessons learned, and unintended consequences of the implementation. Information on the level of training (undergraduate vs graduate) and programme discipline (medicine, dentistry, veterinary) were also collected. The survey was developed by the authors and vetted by a subgroup of assessment specialists participating in the study.

\section{Data analysis}

Survey responses were analysed using a deductive thematic analysis (Boyatzis 1998; Braun and Clarke 2006). Given that the twelve principles of programmatic assessment share similar theoretical underpinnings (Heeneman et al. 2015; Torre et al. 2020) and have a high degree of interrelatedness, the programmatic assessment principles were used as a framework (or sensitizing concepts) for the thematic analysis (Brooks et al. 2015). Using an iterative collaborative thematic analysis process, two of the authors (DT, NR) read through the data looking for emergent new themes, met to discuss the themes developed, and then further refined them to build a common understanding of the data and identify relationships within and across themes. Ultimately, data were organised into three overall meaningful clusters (Figure 1).

\section{Results}

Implementation data were collected from 15 programmes (eight undergraduate (primary degree) medical education, three postgraduate (residency or vocational) medical education, one undergraduate dentistry and two undergraduate veterinary programmes) (Table 1). All but one of the programmes involved in the consensus statement survey, also took part in the implementation survey.

We present our findings in two parts. Firstly, we describe the implementation of programmatic assessment principles across different institutions reporting on implementation components that were common across programmes (mentioned by more than $50 \%$ of respondents) and provide examples of how the principles were translated into educational practices (Part 1). Secondly, we present findings on enablers, barriers, lessons learned, and unintended consequences of the implementation of programmatic assessment (Part 2).

For each theme, we present a table which identifies implementation components related to principles, and then provide specific examples from five programmes covering different countries and contexts. Our aim is to present a comprehensive and meaningful spectrum of implementation descriptions that captures the variability of implementation data in different contexts. It is important 


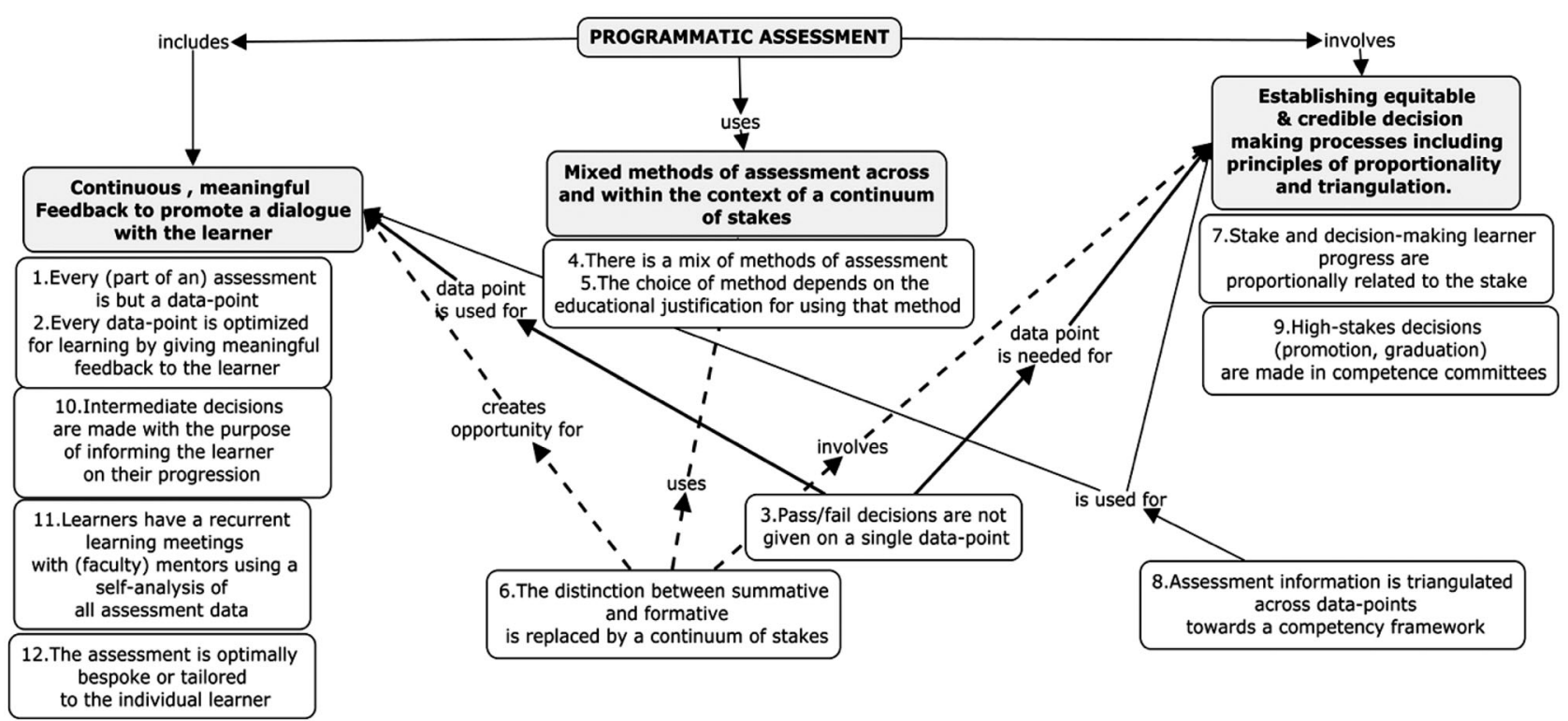

Figure 1. Principles of programmatic assessment grouped by three implementation themes.

Table 1. Programmes participating in part 2 PA consensus statement by discipline, level of training, programme size, and country.

\begin{tabular}{llll}
\hline Discipline & $\begin{array}{c}\text { Undergraduate (UG) or } \\
\text { post-graduate (PG) }\end{array}$ & $\begin{array}{c}\text { Number of } \\
\text { learners }\end{array}$ & \multicolumn{1}{c}{ Country } \\
\hline Dentistry & UG & $377 /$ year & United Kingdom \\
Medicine & PG & 462 & Australia \\
Medicine & PG & 136 & Canada \\
Medicine & PG & 38 & Canada \\
Medicine & UG & $360 /$ year & Australia \\
Medicine & UG & $200 /$ year & Australia \\
Medicine & UG & $260 /$ year & Canada \\
Medicine & UG & $288 /$ year & Canada \\
Medicine & UG & $50 /$ year & Netherlands \\
Medicine & UG & $350 /$ year & Netherlands \\
Medicine & UG & $300 /$ year & New-Zealand \\
Medicine & UG & $280 /$ year & United Kingdom \\
Medicine & UG & $32 /$ year & USA \\
Veterinary & UG & $30 /$ year & Canada \\
Veterinary & UG & $225 /$ year & Netherlands \\
\hline
\end{tabular}

to note, while we have included specific principles under each of our three themes, we acknowledge that all principles in the model are interconnected and function as interacting parts of a larger programmatic assessment system.

\section{Part 1 - implementation of programmatic assessment principles}

The implementation of the 12 principles of programmatic assessment were grouped under three themes: (1) Continuous and meaningful feedback to promote a dialogue with the learner for the purpose of growth and development; (2) Mixed methods of assessment across and within the context of a continuum of stakes; and (3) Establishing equitable and credible decision-making processes including principles of proportionality and triangulation.

Theme 1: Continuous and meaningful feedback to promote a dialogue with the learner for the purpose of growth and development:

There were nine implementation components (Table 2) aligned with principles 1, 2, 10, 11 and 12 under this theme.

Most programmes reported an implementation in which every assessment contributed a single data-point optimised for feedback, whether that was occurring in real time or at specific intervals. The delivery of narrative feedback using aggregated data from multiple assessments was often mentioned. Feedback was delivered to learners in verbal and/or written form, with the intent of providing support for reflection and to guide future learning. The majority of programmes highlighted the importance of developing a relationship between supervisor and learner to enhance feedback quality and foster a process of meaningful reflection and goal setting.

All programmes reported the implementation of a system in which learners were assigned a coach or advisor to support their progress and achievement. The majority of programmes indicated that coaches had recurrent meetings with learners (quarterly or biannually); however, in some instances, meetings were more ad hoc in response to poor academic performance or concerns being flagged. Most programmes used some type of electronic portfolio to gather, store, and readily access assessment data to facilitate faculty-learner transactions. Intermediate reviews were performed for the purpose of assessing progression, promoting learners' reflection about their longitudinal learning trajectory, formulating learning plans and and/or additional remediation if needed.

Most programmes reported learners' engagement and participation in the assessment process upon entering the program. In some cases, programmes required learners to respond to feedback and develop individual learning plans, with an emphasis on self-reflection. In some programmes, teaching was tailored to meet individual learning priorities whilst encouraging learners to take agency for their own development. Generally, however, this principle was only partially implemented due to the logistical and organisational challenges of individualising learning for a high number of learners.

Theme 2: Mixed methods of assessment across and within the context of a continuum of stakes:

There were four common implementation components (Table 3) aligned with principles 4, 5 and 6 under this theme.

All programmes indicated that no single type of assessment can capture all competencies and that implementations involved the use of multiple assessment methods and tools. 


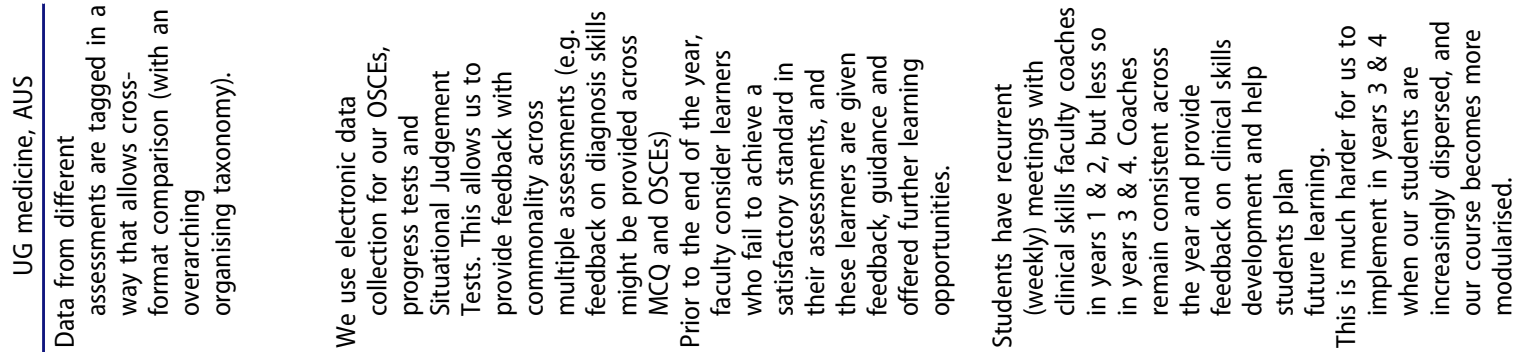

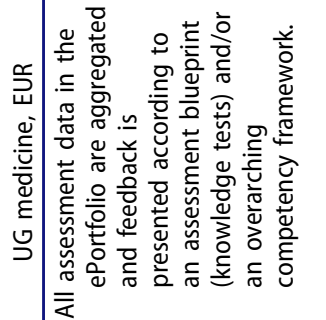

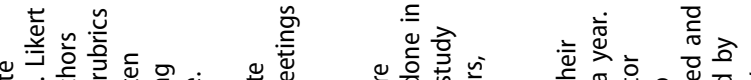

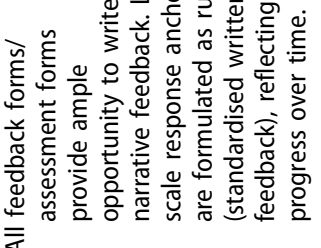

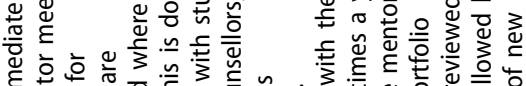

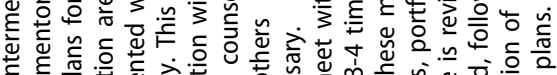

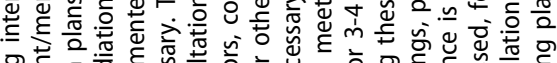

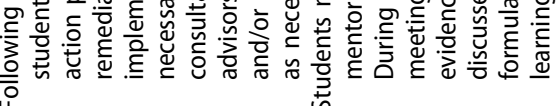

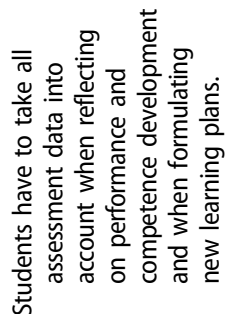

㐫

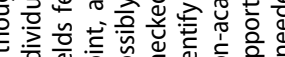

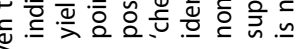

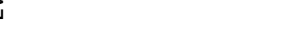

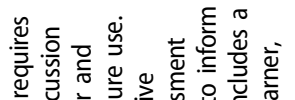

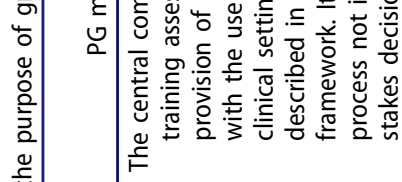

훈



妾

离

势

힐

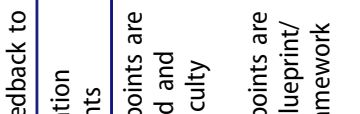

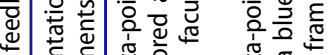

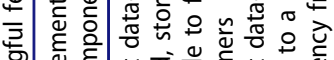

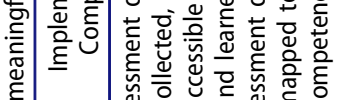

表

范

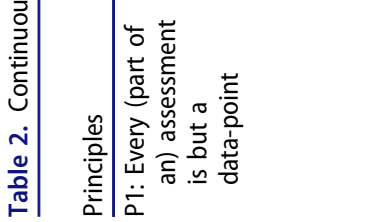

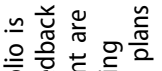
政娄

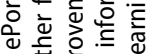
흠을 음

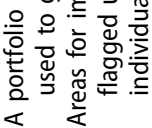

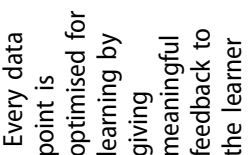

$\ddot{\alpha}$ 政

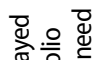
它

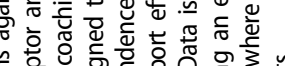

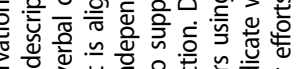

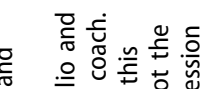

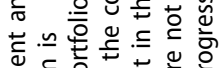

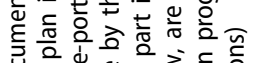

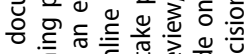

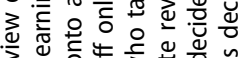

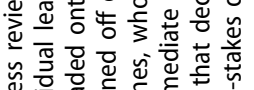

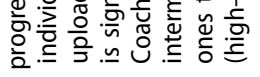

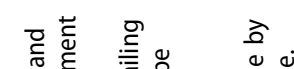

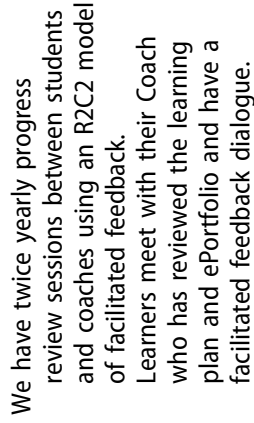

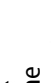

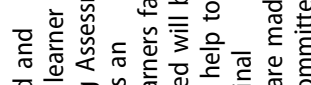

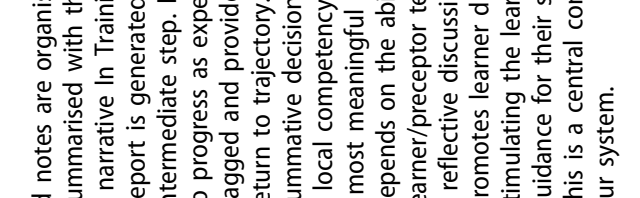

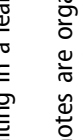$$
\text { 更 }
$$

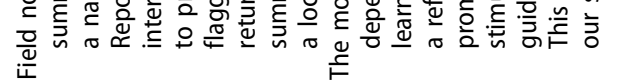

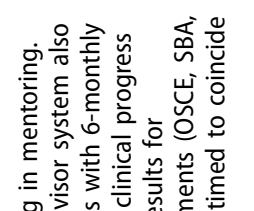

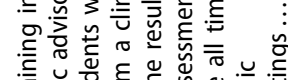

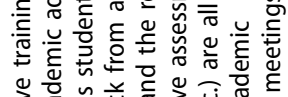

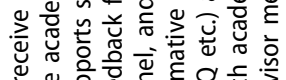

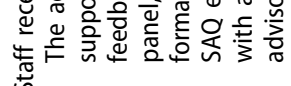

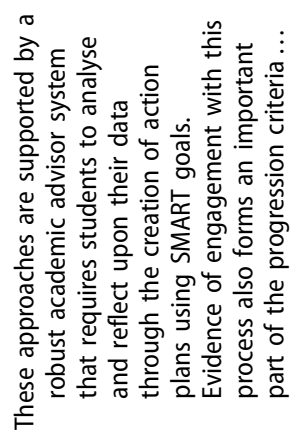

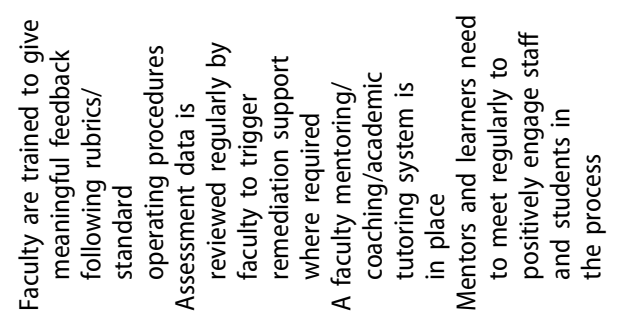

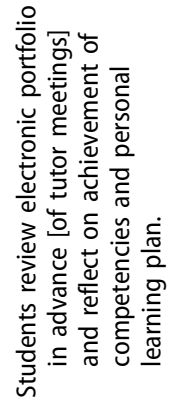

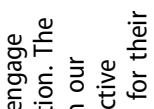

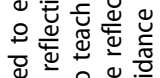
岁产 记 要 完 응 은

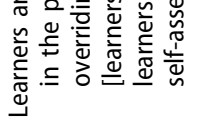

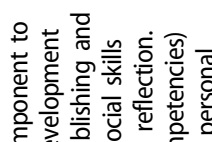
总离

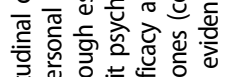

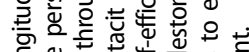

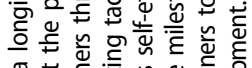

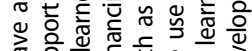

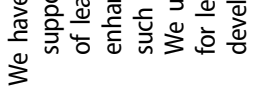

㐫就

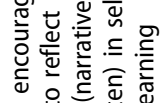

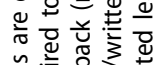

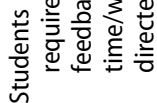

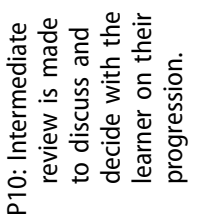

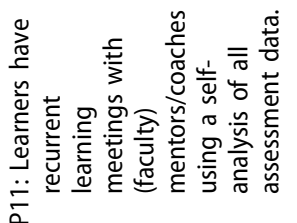




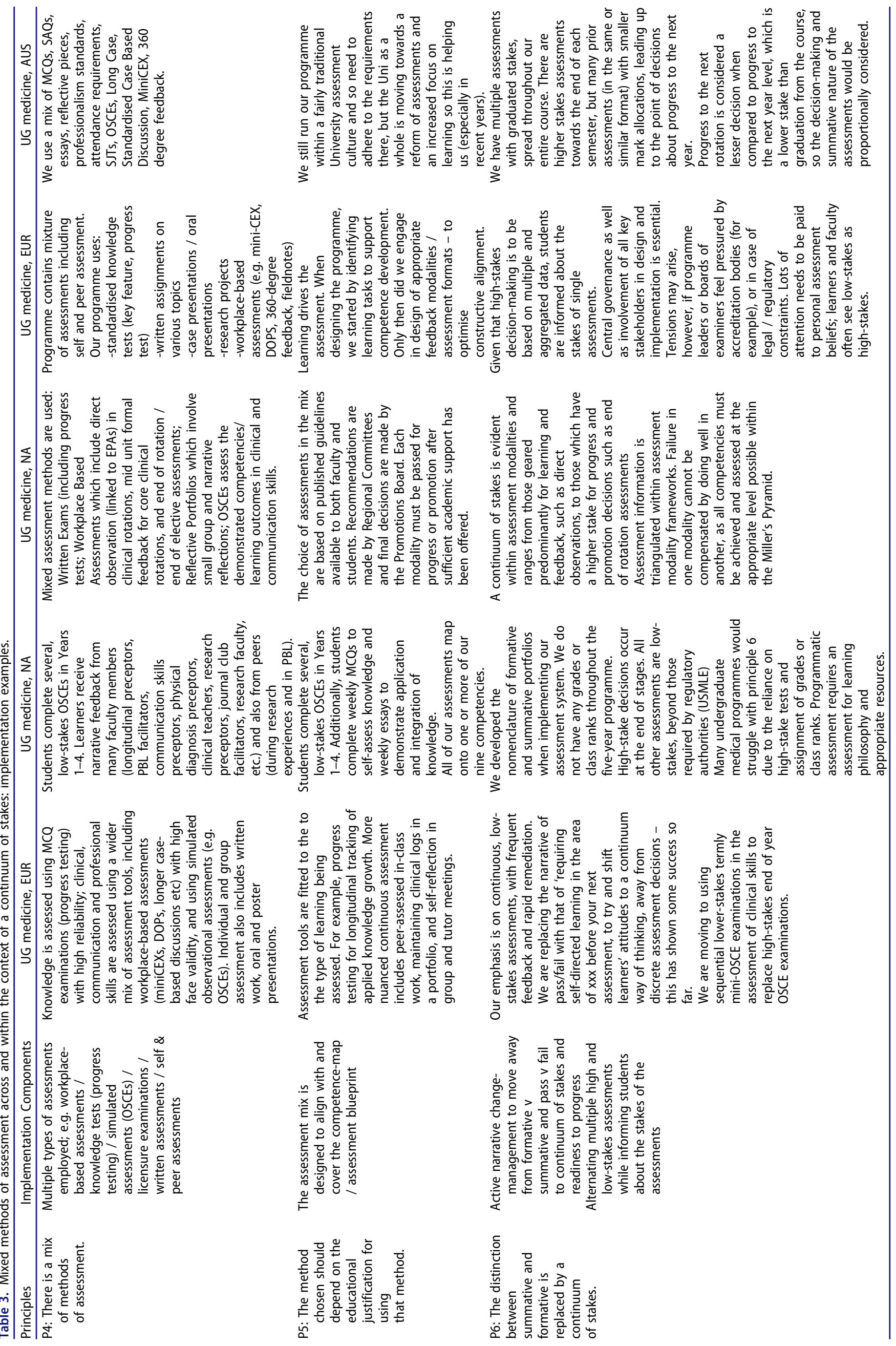


The variety of assessments implemented allowed for the gathering of both numerical and narrative data that could be used to provide rich and meaningful feedback to learners. Nearly all programmes mentioned that the mix of assessments was designed against a competency framework, and many indicated adherence to constructive alignment and a programme of assessments designed using Miller's pyramid. Most programmes indicated multiple lowstakes workplace-based assessments as particularly important for assessing real-world situational competence, and most reported the use of simulated assessments (e.g. OSCEs) and written assessments (including progress testing) in the knowledge domain.

Most programmes reported the implementation of a continuum of stakes by the use of multiple low- stakes assessments with frequent delivery of feedback (e.g. direct observation workplace-based assessments or sequential mini-OSCEs) interwoven with high-stakes assessments performed at key developmental transition points in the curriculum (e.g. progression exams before entering clinical rotations, final written exams and OSCEs or national licensing exams). This principle had a wide range of implementations, related to timing and progressive combination of low- and high-stakes assessment. Furthermore, providing students with information about the stakes of assessment and explaining how such a continuum of stakes was going to be operationalised was a frequent implementation strategy in the majority of programmes.

Many programmes highlighted the importance of providing information and guidance to encourage stakeholders to think of assessments as being on a continuum of stakes rather than pass/fail. The implementation of multiple lowstakes assessments with feedback prior to high-stakes assessments allowed programmes to begin shifting from a predominant summative assessment approach to a language and culture of assessment for learning through a continuum of stakes.

Theme 3: Establishing equitable and credible decisionmaking processes including principles of proportionality and triangulation:

There were ten common implementation components (Table 4) aligned with principles 3, 7, 8 and 9 under this theme.

For most programmes, high-stakes decisions (e.g. decisions to progress to the next year of training) were made by a committee based on the review and aggregation of multiple assessment data points collected over time. The timing of high-stakes decisions varied by programmme, with some occurring yearly and others biannually or quarterly. Low-stakes decisions (e.g. a decision on a performance of a direct observation of clinical skills) were based on a single or few assessment data points for the purpose of providing feedback to promote learners' growth and development. However, the majority of programmes indicated that when implementing the principle of proportionality low-stakes assessments would be one of the data points that contributed to a high-stakes decision.

Most programmes reported that implementation of highstakes decisions involved some form of a committee and described some version of a two (or more) stage committee decision-making process (e.g. a progress committee makes a first determination about a learner's performance after reviewing all assessment data, and then an examiner committee reaches a final decision). The typically described committee consisted of a group of independent, trained examiners who review learners' assessment data, often collected in an eportfolio, and then engage in a data-driven deliberation to reach a final decision. Most programmes highlighted the need for well communicated, pre-determined procedures, rules or rubrics to guide decision-making and to ensure transparency and credibility, often with direct learners' engagement and participation in a shared decision-making process.

Triangulation was reported by most programmes as important in the high-stakes decision-making process and was generally implemented by synthesizing data from multiple assessment modalities that had been previously mapped to an overarching competency-based framework.

Whilst all programmes described decision-making processes that included the monitoring of longitudinal performance of all learners, the majority reported that most decisions were clear-cut and did not require much, if any, discussion, with outcomes not coming as 'surprises' for faculty or learners. The majority of programmes reported that in depth committee discussions usually focused on a relatively small number of learners for whom there were concerns over meeting performance standards.

\section{Part 2 -enablers, barriers, and lessons learned}

There was agreement that the strongest enabler for programmatic assessment implementation is strong leadership with a clear vision supported by committed faculty. The majority of programmes mentioned that having clearly communicated, accessible goals and delivery plans was an essential enabler. Several programmes mentioned that investing in the development of a design and implementation plan was fundamental to the success of the implementation.

A centralised oversight coupled with the creation of an assessment working group who would promote the philosophy of programmatic assessment and engage and communicate with all stakeholders were key enablers in the implementation process. Having a clear vision of the assessment system, involving learners in the assessment process, establishing assessment goals, and implementing defensible processes and procedures were all mentioned as necessary steps to enable successful implementation.

Another common enabler (and barrier) was the level of buy-in and engagement of all stakeholders in the design, development and delivery of the implementation process. Fundamental to the success was an ongoing commitment of resources to train faculty and learners on the principles, operationalisation of programmatic assessment, coupled in the longer term, with a commitment to invest in software (e-Portfolios) to support feedback delivery, learners' agency, and triangulation procedures for decision-making. The creation of an ongoing faculty development programme as part of the implementation, focusing on assessment literacy, a good knowledge of the competency framework in use and providing feedback for learning, was a critical enabler. Such effort clearly involved the leveraging of resources and leadership support. Investing resource into developing a strong coaching system to evaluate and support learners' progress and achievement was also mentioned. 


\begin{tabular}{|c|c|c|c|c|}
\hline & 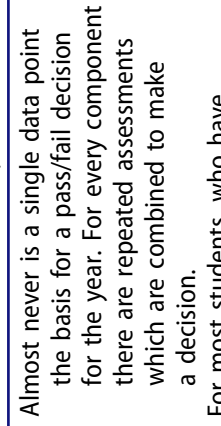 & 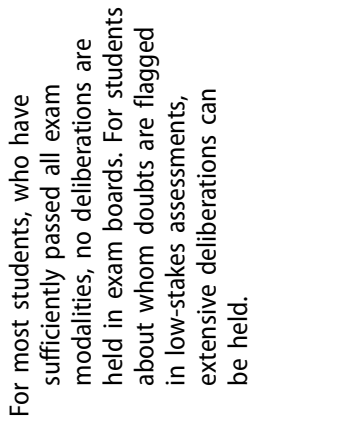 & 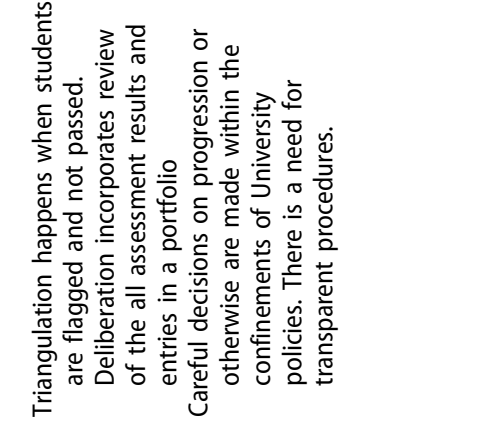 & 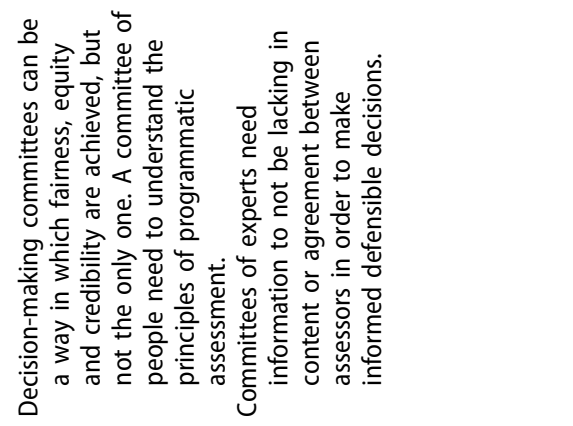 \\
\hline 0 & 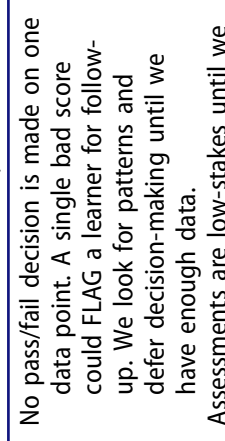 & 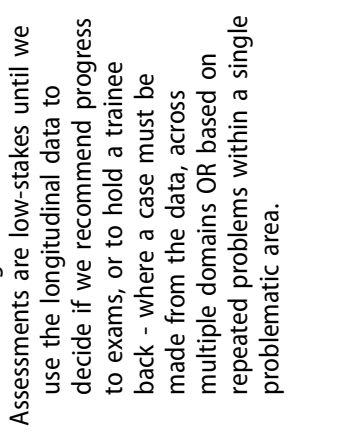 & 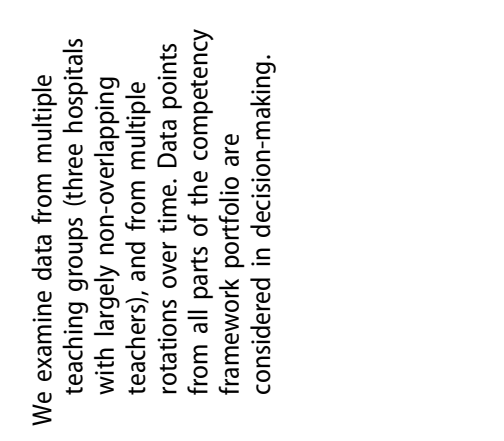 & 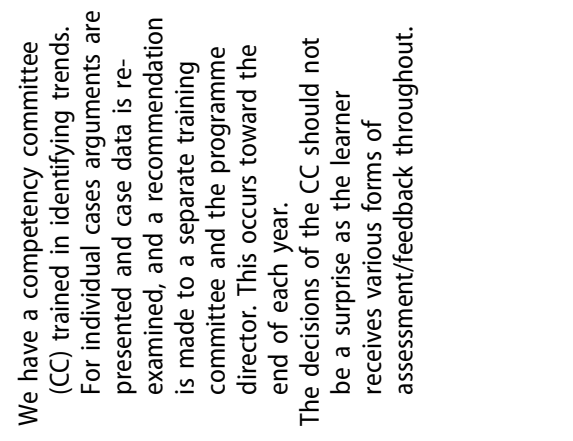 \\
\hline & 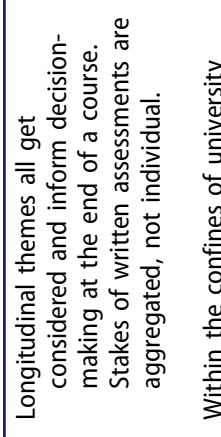 & 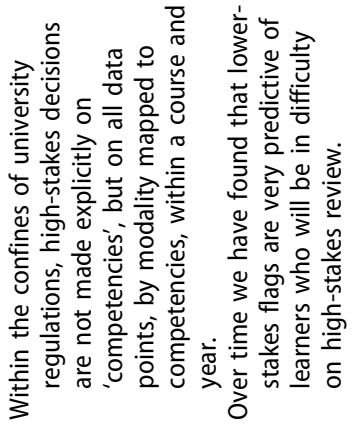 & 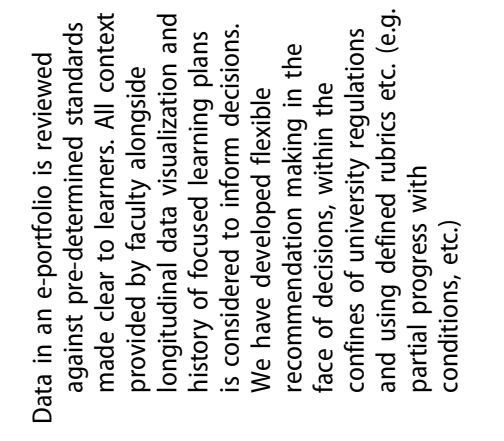 & 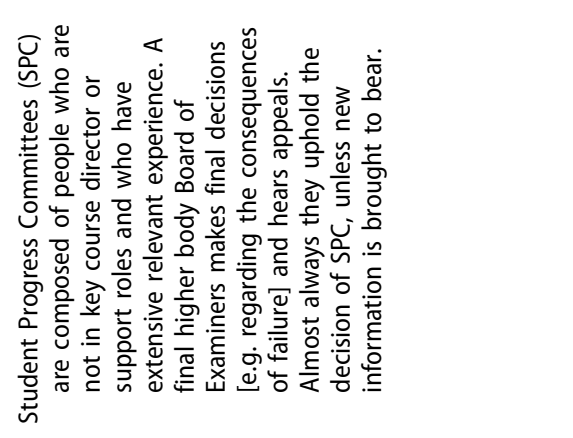 \\
\hline & 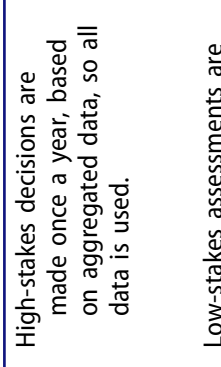 & 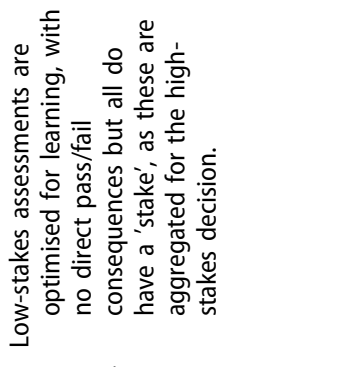 & 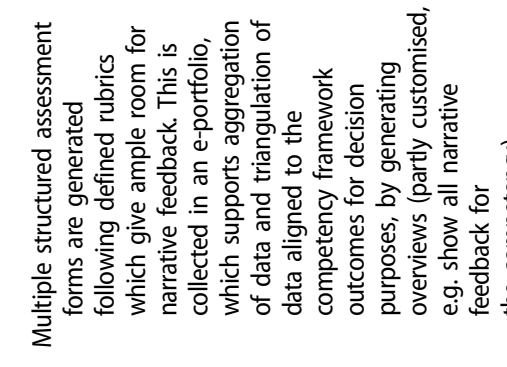 & 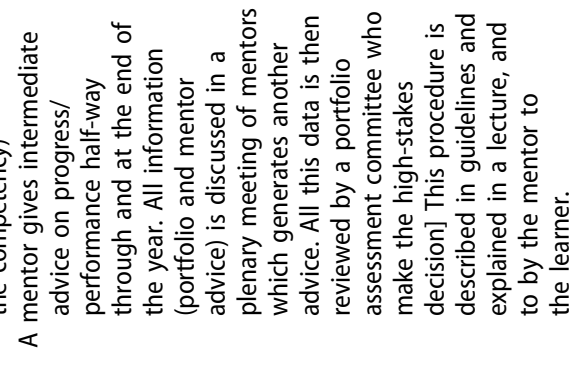 \\
\hline & 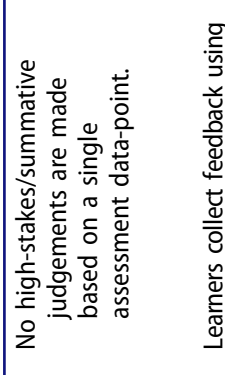 & 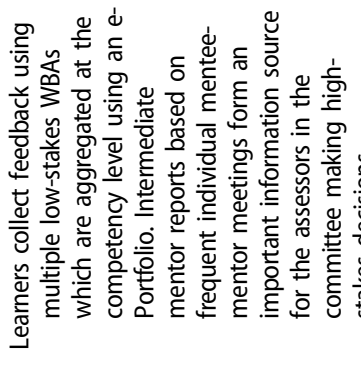 & 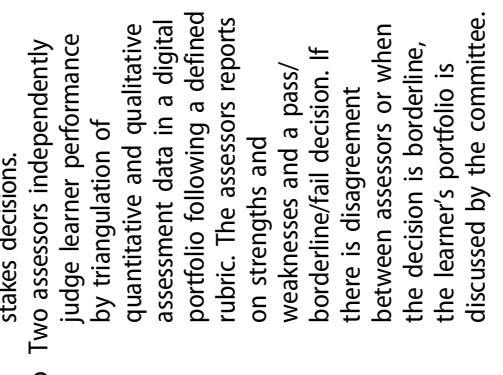 & 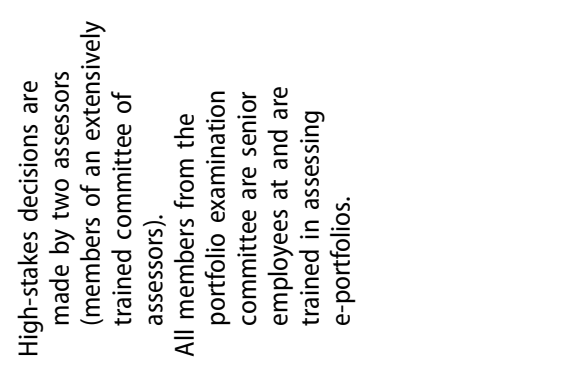 \\
\hline & 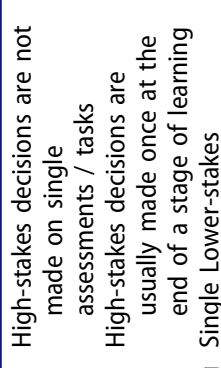 & 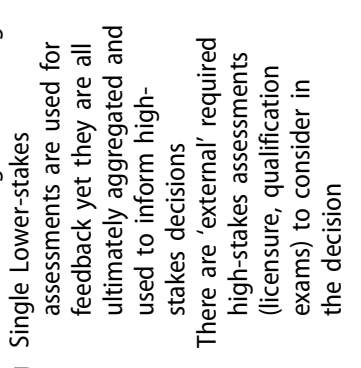 & 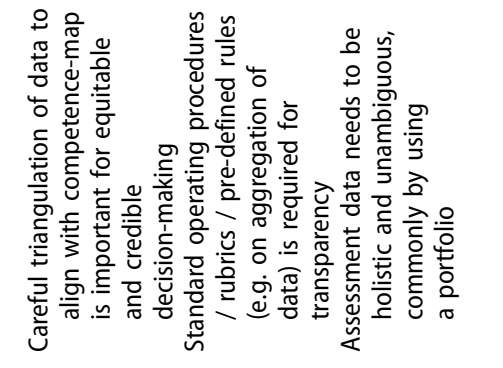 & 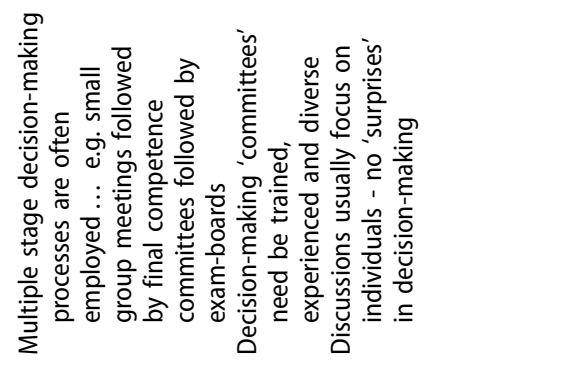 \\
\hline & 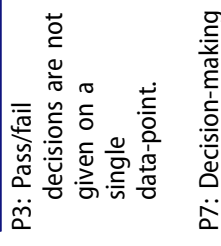 & 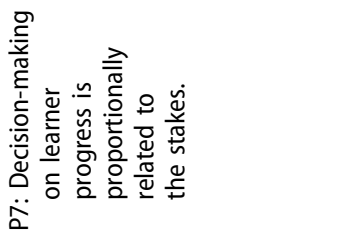 & 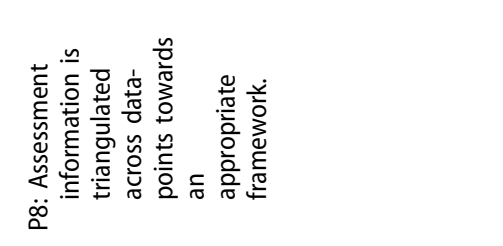 & 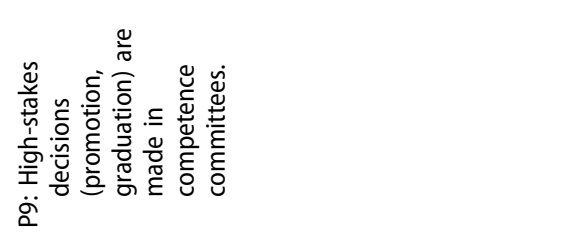 \\
\hline
\end{tabular}


Where programmes had implemented programmatic assessment in new programmes or in conjunction with a full curriculum review, it was evidently a smoother process than in programmes which were attempting to integrate within established systems. Careful constructive alignment with detailed curriculum mapping was noted as being easier in new implementations.

The commonly mentioned barriers to implementation to a large extent mirrored the enablers. The level of organisational commitment to change, demands on faculty time, and availability of resources were cited by all responders as barriers, but not necessarily insurmountable ones. The biggest barrier to successful implementation was a general resistance to change, with most programmes mentioning the difficulty in changing embedded educational and assessment cultures, expectations and attitudes - of faculty, educators and learners. A shift in the mindset and culture of assessment among learners was identified as a significant a barrier, as was a lack of planning and provision of resources for faculty professional growth. The lack of strong leadership committed to making changes at the system level was recognised as a significant obstacle to implementation by many institutions.

Institutional policies and requirements from accreditation and regulatory bodies were reported as potential barriers. For example, the requirement on learners to pass a high-stakes national licensing exam at some point in their training was seen as counter-intuitive to the theoretical principles and as a hindering factor to the acceptability of and learners' buy-in to programmatic assessment. However, most programmes were able to make changes and implement programmatic assessment within the boundaries and regulations set by university policies and national accreditation bodies.

The implementation of programmatic assessment afforded programmes the opportunity to learn a number of lessons related to learners, faculty, and their educational system. Programmes learnt that involving learners in programmatic assessment innovation is just as important as buy-in from faculty members. Most programmes described that implementing programmatic assessment helped leverage the learning function of assessment and provided more opportunity to identify struggling learners early on, thereby allowing more time for improvement and for targeted and robust interventions. Furthermore, learners were more likely to seek feedback proactively and take ownership of their own learning while faculty were more comfortable with assessing, discussing, and making decisions about learners' progress and performance.

Many programmes described having learnt the importance of engaging regularly with stakeholders to maintain a shared vision, frequently communicating the why, what, and how change is going to occur. Most respondents reported that it took perseverance, strong leadership, and institutional commitment to implement and recognise the educational gains of programmatic assessment. Several respondents also recognised that understanding the contextual factors and the cultural landscape of the institution was vital to enact a process of change. Changes occurring in one particular context may not be feasible or as successful in another. Many programmes indicated that programmatic assessment is a fundamental disruption from traditional assessment and requires a major paradigm shift; therefore, creating a context supportive of change is imperative for success.

Respondents indicated several unintended consequences of the implementation of programmatic assessment. For some programmes, implementing programmatic assessment provided a new insight into the curriculum and allowed identification of areas for improvement. The change to programmatic assessment enhanced feedback literacy and helped students understand how to best utilise the feedback they received from faculty.

One programme reported that instead of having multiple data points and few decision points in accordance with programmatic assessment and assessment for learning principles, for some reason, there was an increase in the number of decision points, resulting in students' perception of being part of an environment of constant summative assessment.

Some programmes reported an increase in faculty time and workload, particularly at the inception of programmatic assessment implementation, but noted that the longer-term benefits in terms of the better communication and dialogue between faculty (coaches) and learners outweighed the initial investment of time resource.

Several programmes indicated that their implementation of programmatic assessment coincided with an unexpected increase in the use of technology enhanced assessment; the use of an e-portfolio and the addition of portable technology to collect experiences allowed learners to share their work, promoting reflection and creating a safe environment to interact with faculty. Additional details on enablers and barriers are reported in Supplementary Appendix 1.

\section{Discussion}

There were a wide range of implementation descriptions across different programmes, yet overall components of implementation, enablers and barriers were similar across disciplines and undergraduate and postgraduate programmes. The actual implementation of the 12 programmatic assessment principles remained, for the most part, faithful to the original enunciation and rationale. For example, most programmes had some form of assessment committee for high-stakes decisions; however, what the committee was named, what procedure was used to analyse data, or how often the committee met was found to have a range of implementations across programmes. The use of review committees for high-stakes decisions, the utilisation of mixed methods of assessments, the implementation of every assessment as a data point optimised for feedback, and the development of a continuum of stakes were just some of the principles translated into practice within a range of implementations across different programmes and educational contexts.

The critical role of implementation in programmatic assessment has been discussed (Bok et al. 2013), and it has been suggested that the quality of implementation defines the success of programmatic assessment (Van Der Vleuten et al. 2019). Key implementation elements include design based on principles and participation (Jamieson et al. 2017; Schuwirth et al. 2017), the role of a portfolio to integrate 
assessments (Dannefer and Henson 2007), the role of a committee in high-stakes decision-making (Van Der Vleuten et al. 2015), students' perception of the assessment (Heeneman et al. 2015; Schut et al. 2018), the relationship between learners and faculty (Schut et al. 2021), and the parallel implementation of curriculum and programmatic assessment (Freeman and Ricketts 2010; Ricketts and Bligh 2011). More recently, Jamieson et al. (2021) found that a successful implementation of programmatic assessment transformed the supervisors' role and their views of assessment practices, whilst enhancing the supervisor-learner relationship. Adequate implementation of programmatic assessment is also critical to provide data to inform outcomes of competency based medical education (Hauer et al. 2018; lobst and Holmboe 2020; Misra et al. 2021).

The implementation descriptions of the consensus group contribute to enhance our knowledge and understanding of the spectrum of implementation related to the principles of programmatic assessment. Implementation is a process not an isolated event (Hall and Hord 2015). Most programmes reported that the implementation process of programmatic assessment takes time (years not months), needs a strategic well-designed and well budgeted plan, requires strong leadership and support, and demands a shared vision of change and a culture shift across the entire educational enterprise. Further, it involves an ongoing programme of faculty development and coaching with continuous monitoring of progress and assistance to face and resolve challenges. Implementation of programmatic assessment requires sustained commitment of resources and ongoing vigilance to maintain the integrity of its key components.

Designing a plan, securing leadership support, allowing opportunities for flexibility and adjustments, a shared belief of relevance and value among stakeholders are all important factors reported in the managing change literature (Gale and Grant 1997; Schneider 2014). The descriptions of implementations of programmatic assessment are aligned with several of these factors, yet adaptation to context and its complexities seems to emerge as an essential ingredient for a successful implementation of the principles of programmatic assessment across programmes.

Assessment as a continuum of stakes (principle 6) had a particularly wide range of implementations. Many programmes implemented and executed plans to explain and educate learners about the meaning of this principle, including how it was going to be operationalised, promoting a culture of growth and improvement that, in some cases, led to the elimination of grades and class ranks. This approach created opportunities to foster learners' agency with the assessment process. This was aligned with previous evidence suggesting that a continuum of stakes is perceived by learners as complex and is strongly related to their perception of being able to control and take agency of the assessment process (Bok et al. 2013; Schut et al. 2018).

Learners' agency is a complicated process; it takes effort and requires mentorship and support to counteract the pressure of established social norms and cultural beliefs (Watling et al. 2021). Teacher-learner relationships play a critical role in learners' assessment perceptions; teachers who show a less dominant approach in the assessment relationship enable learners' agency, promoting a positive learner perception of assessment for learning (Schut et al. 2020a). If teachers exert control over the low-stakes assessment process it can hinder the learning function of assessment and generate tensions in the teacher-learner relationship (Schut et al. 2020b). Such tensions can be relieved in the use of progress committees or clinical competency committees, where important assessment decisions have a collective responsibility rather than that of a single individual. The use of a progress or competency committee was a key component in almost all descriptions of the implementations of programmatic assessment.

In the implementation of programmatic assessment, fostering a feedback seeking behaviour with a learning goal orientation (focused on growth and improvement) rather than a performance goal orientation (focused on gaining a positive judgement and garnering recognition of their own ability or on avoiding negative feedback) (Bok et al. 2013; Teunissen and Bok 2013) may promote learners' acceptance and affect their perceptions of assessment as a continuum of stakes, ultimately facilitating the implementation of this principle. It has also been suggested that reflection is the path to acceptance of feedback that is out of line with learners' self-assessment (Sargeant et al. 2008).

One of the principles, (principle 12, assessment tailored to the individual learner), proved to be challenging to fully implement, particularly in programmes with a large number of learners. However, the implementation of the other principles did not seem to be significantly affected by the size of a programme, at least to the extent that a principle could not be at all implemented because of a large programme size.

One of the widely recognised barriers to implementation was the need for a paradigm shift in assessment culture within the organisation, amongst leaders, learners and educators. Programmes which have longer-standing established implementations reported more success whereas newer implementations are still experiencing this cultural shift, and there were noticeable differences in the extent of this across contexts. Understanding the organisational and cultural context of programmes is essential for the implementation and sustainability of any intervention or change because all stakeholders are an integral part of a shared environment (Damschroder et al. 2009; Marks et al. 2010). Context consists of a number of interacting variables and set of circumstances that surround a specific implementation. All parts which shape the context of a system need to be legitimised and involved.

The emerging concepts of self-theories which impact personal motivation and growth mindset, built on the social cognitive model proposed by Dweck (Dweck and Leggett 1988) can be considered in relation to stakeholders' attitudes to changing culture. The way in which selftheories may impact on Health Professions Education has been explored (Teunissen and Bok 2013), and the model has been generalised to organisations (Canning et al. 2020). External attributes (such contextual education factors) may be considered as 'fixed' (entity theory) or 'adaptable' (incremental theory) depending on the mindset of the stakeholder. If stakeholders are incremental theorists, they are more likely to positively embrace change by seeking improvement and believing that external attributes can 
change for the better. Conversely, if stakeholders are entity theorists, they will be more resistant to engage with or initiate change.

Programmes that endorse and adopt a growth mindset culture will motivate learners and educators to take on more challenges and initiate change, encourage stakeholders to view 'failures' as learning opportunities and inspire confidence in innovation (Dweck 2019; Canning et al. 2020). Fostering an incremental theory approach and a learning goal orientation within individual learners and teachers, and at the organisational level would be beneficial for the implementation of programmatic assessment. There are some encouraging results in the literature about potential educational interventions to promote a growth mindset (Aronson et al. 2002; Blackwell et al. 2007). However, more research is needed to understand how to promote a growth mindset more effectively and systematically among individuals and across organisations.

\section{Conclusions}

The majority of the theoretical programmatic assessment principles achieved by consensus were successfully implemented by most programmes. A few principles like using a true continuum of stakes (principle 6), proportionality about decision-making processes (principle 7) or procedures for triangulation of data (principle 8) had a wider spectrum of implementations. Principle 12 (assessment tailored to the individual learner) proved to be the most challenging, but not impossible, to fully implement. Overall a description of the implementation of programmatic assessment across multiple educational contexts provided new insights to gain a better understanding of programmatic assessment and shed some light on how it can be best operationalised to achieve its full educational benefits. Implementation of programmatic assessment takes time, needs strong leadership commitment and support, and involves a continuous effort at the individual and organisational level. A paradigm shift from the mindset of a traditional assessment approach to that of a programmatic assessment culture by faculty, and students, coupled with the constraints posed by university policies and procedures, were significant yet not insurmountable barriers to implementation. Programmatic assessment implementation provided a new insight into the curriculum, allowing programmes to identify areas for improvement. It also enhanced feedback literacy among students and faculty, improved feedback quality, and allowed early identification and support of struggling learners. Successful implementations of the principles of programmatic assessment (mix of methods of assessment, triangulation, longitudinality, and proportionality) improve the data available for decision making processes, whilst keeping the amount of data and documentation manageable and meaningful.

\section{Recommendations for future work}

There are a number of recommendations for future research. First, investigate further the critical factors that may influence the implementation of specific principles in order to enhance their implementation. The role of required high-stakes assessments conducted by external regulatory bodies (licensure, qualification exams) on the implementation of specific principles needs to be further determined and explored. Second, inquire about the development of effective faculty development programmes that may enhance the quality of implementation, particularly about key aspects of programmatic assessment such as feedback delivery and programmatic assessment literacy. Further, ways to promote students' understanding, adoption, and utilisation of programmatic assessment practices should be sought. This could include examination of explicit and hidden curriculum messages that might cause learners cognitive dissonance, for example the reality of high-stakes consequences of professional training programmes, such as success in residency matches. Third, additional inquiries should be conducted about key contextual and cultural factors that affect implementation and how such factors influence implementation across different institutions worldwide. Finally, more research is needed to evaluate the impact of a complete and effective implementation of programmatic assessment, learner competency and wellness, and the extent to which this approach ultimately impacts health care outcomes at the patient and system level.

\section{Acknowledgements}

This work was made possible thanks to the efforts of individuals, including the authors, who took the time to complete the survey questionnaire describing implementation experiences in their programmes. As such, the authors would like to acknowledge and thank the following: Marjan Govaerts, (Maastricht, the Netherlands) Lambert Schuwirth (Flinders University, Australia), Teresa Chan (McMaster, Canada), Paul Dilena (General Practice, Parkside, Australia), Vincent Arockiasamy (University of British Columbia, Canada) and Kent Hecker (University of Calgary, Canada).

\section{Disclosure statement}

The authors report no conflicts of interest. The authors alone are responsible for the content and writing of this article.

\section{Notes on contributors}

Dario Torre, MD, MPH, PhD, Professor of Medicine and Associate Director for Program Evaluation and Long Term Outcomes at Uniformed Services University of Health Sciences in Bethesda, Maryland, USA.

Neil Rice, Head of Psychometrics and Informatics, University of Exeter, College of Medicine and Health, Exeter, UK.

Anna Ryan, MBBS, PhD, Associate Professor, Director of Assessment Department of Medical Education, Melbourne Medical School, University of Melbourne, Australia.

Harold Bok, Faculty for Veterinary Medicine, Centre for Quality Improvement in Veterinary education, Department of Veterinary Medicine, Utrecht University, Utrecht, The Netherlands.

Luke J. Dawson, BSc, BDS, PhD, FDSRCS(Eng), FHEA, MA (TLHE) NTF, Professor of Dental Education, Director of Undergraduate Education, School of Dentistry, Liverpool, UK.

Beth Beirer, MD, Director of Assesmsnent and Evaluation, Cleveland Clinic Learner College of Medicine of Case Western University, Cleveland, OH, USA.

Tim J. Wilkinson, $\mathrm{MB}, \mathrm{ChB}, \mathrm{MD}, \mathrm{PhD}$ (Otago), M Clin, Ed(UNSW), FRACP FRCP(London), FANZAHPE, Director of the University of Otago MBChB 
programme, Education unit, University of Otago, Christchurch, New Zealand.

Tom Laughlin, MD, Associate Professor of Family Medicine Department of Family Medicine, Dalhousie University, Halifax, Canada.

Kieran Veerapen, MD, Associate Professor of medicine, Assistant Dean for Faculty Development, University of British Columbia, Vancouver, BC, Canada.

Glendon R. Tait, MD, MSc, Director of Student Assessment, MD Program at the University of Toronto; Associate Professor Department of Psychiatry and practices Consultation-Liaison Psychiatry with Sinai Health System, and The Wilson Centre, University of Toronto, Canada.

Sylvia Heeneman, PhD, Professor of Health Profession Education at the School of Health Profession Education, Department of Pathology, Faculty of Health, Medicine and Life Sciences, Maastricht University, the Netherlands.

Adrian Freeman, MD, MMedSci, FRCGP, FAcadMed, Professor of Medical Education at University of Exeter Medical School, examiner for the Royal College of General Practitioners, President of the European Board of Medical Assessors and Deputy chair of the GMC Panel for Tests of Competence, University of Exeter, College of Medicine and Health, Exeter, UK.

Cees van der Vleuten, PhD, Professor of Education, Faculty of Health Medicine and Life Sciences, Maastricht University, The Netherlands.

\section{ORCID}

Dario Torre iD http://orcid.org/0000-0002-4924-4888

Neil E. Rice (iD http://orcid.org/0000-0002-9718-1316

Beth Bierer (iD http://orcid.org/0000-0002-7952-8822

Tim J. Wilkinson (ID http://orcid.org/0000-0002-4080-4164

Cees van der Vleuten (iD http://orcid.org/0000-0001-6802-3119

\section{References}

Aronson J, Fried CB, Good C. 2002. Reducing the effects of stereotype threat on African American college students by shaping theories of intelligence. J Exp Soc Psychol. 38(2):113-125.

Blackwell LS, Trzesniewski KH, Dweck CS. 2007. Implicit theories of intelligence predict achievement across an adolescent transition: a longitudinal study and an intervention. Child Dev. 78(1):246-263.

Bok HG, Teunissen PW, Favier RP, Rietbroek NJ, Theyse LFH, Brommer $\mathrm{H}$, Haarhuis JCM, van Beukelen P, van der Vleuten CPM, Jaarsma DADC. 2013. Programmatic assessment of competency-based workplace learning: when theory meets practice. BMC Med Educ. 13:123.

Bok HG, Teunissen PW, Spruijt A, Fokkema JP, van Beukelen P, Jaarsma DA, van der Vleuten CP. 2013. Clarifying students' feedback-seeking behaviour in clinical clerkships. Med Educ. 47(3):282-291.

Boyatzis RE. 1998. Transforming qualitative information: thematic analysis and code development. Thousand Oaks (CA): Sage.

Braun V, Clarke V. 2006. Using thematic analysis in psychology. Qual Res Psychol. 3(2):77-101.

Bierer SB, Dannefer EF, Tetzlaff JE. 2015. Time to loosen the apron strings: Cohort-based evaluation of a student-driven remediation model at one medical school. J Gen Intern Med. 30(9):1339-1343.

Brooks J, McCluskey S, Turley E, King N. 2015. The utility of template analysis in qualitative psychology research. Qual Res Psychol. 12(2) 202-222.

Canning EA, Murphy MC, Emerson KT, Chatman JA, Dweck CS, Kray LJ. 2020. Cultures of genius at work: organizational mindsets predict cultural norms, trust, and commitment. Pers Soc Psychol Bull. 46(4): 626-642.

Cook DA, Brydges R, Ginsburg S, Hatala R. 2015. A contemporary approach to validity arguments: a practical guide to Kane's framework. Med Educ. 49(6):560-575.

Damschroder LJ, Aron DC, Keith RE, Kirsh SR, Alexander JA, Lowery JC. 2009. Fostering implementation of health services research findings into practice: a consolidated framework for advancing implementation science. Implement Sci. 4(1):50- 55.
Dannefer EF, Henson L. 2007. The portfolio approach to competencybased assessment at the Cleveland Clinic Lerner College of Medicine. Acad Med. 82:493-502.

De Jong LH, Bok HG, Kremer WD, Van Der Vleuten CP. 2019. Programmatic assessment: Can we provide evidence for saturation of information? Med Teach. 41(6):678-682.

Driessen EW, van Tartwijk J, Govaerts M, Teunissen P, Van der Vleuten CP. 2012. The use of programmatic assessment in the clinical workplace: a Maastricht case report. Med Teach. 34(3):226-231.

Dweck CS, Leggett EL. 1988. A social-cognitive approach to motivation and personality. Psychol Rev. 95(2):256-273.

Dweck CS. 2019. The choice to make a difference. Perspect Psychol Sci. 14(1):21-25.

Freeman AC, Ricketts C. 2010. Choosing and designing knowledge assessments: Experience at a new medical school. Med Teach. 32(7): 578-581.

Gale R, Grant J. 1997. AMEE Medical Education Guide No. 10. Managing change in a medical context: guidelines for action. Med Teach. 19(4):239-249.

Hall G, Hord S. 2015. Implementing change: patterns, principles and potholes. 5th ed. Upper Saddle River (NJ): Pearson.

Hauer KE, O'Sullivan PS, Fitzhenry K, Boscardin C. 2018. Translating theory into practice: implementing a program of assessment. Acad Med. 93(3):444-450.

Heeneman S, Oudkerk Pool A, Schuwirth LWT, Van der Vleuten CPM, Driessen EW. 2015. The impact of programmatic assessment on student learning: theory versus practice. Med Educ. 49(5): 487-498.

Heeneman S, De Jong L, Dawson L, Wilkinson T., Ryan A, Tait G, Rice N, Torre D, Freeman A, van der Vleuten C. 2021. Ottawa 2020 consensus statement for programmatic assessment - 1 . Agreement on the principles. Med Teach. DOI:10.1080/0142159X. 2021.1957088.

Jamieson J, Jenkins G, Beatty S, Palermo C. 2017. Designing programmes of assessment: a participatory approach. Med Teach. 39(11):1182-1188.

Jamieson J, Hay M, Gibson S, Palermo C. 2021. Implementing programmatic assessment transforms supervisor attitudes: an explanatory sequential mixed methods study. Med Teach. 43(6):709-717.

lobst WF, Holmboe ES. 2020. Programmatic assessment: the secret sauce of effective CBME implementation. J Grad Med Educ. 12(4):518-521.

Marks R, Clarke AM, O'Sullivan M, Barry MM. 2010. Context matters in programme implementation. Health Educ. 110(4):273-293.

Misra S, lobst WF, Hauer KE, Holmboe ES. 2021. The importance of competency-based programmatic assessment in graduate medical education. J Grad Med Educ. 13(2 Suppl):113-119.

Norcini J, Brownell Anderson M, Bollela V, Burch V, Costa MJ, Duvivier R, Hays R, Mackay MFP, Roberts T, Swanson D. 2018. 2018 Consensus framework for good assessment. Med Teach. 40(11):1102-1109.

Norcini J, Burch V. 2007. Workplace-based assessment as an educational tool: AMEE Guide No. 31. Med Teach. 29(9):855-871.

Ricketts C, Bligh J. 2011. Developing a "frequent look and rapid remediation" assessment system for a new medical school. Acad Med. 86(1):67-71.

Sargeant J, Mann K, Van der Vleuten C, Metsemakers J. 2008. "Directed" self-assessment: practice and feedback within a social context. J Contin Educ Health Prof. 28(1):47-54.

Schut S, Driessen E, van Tartwijk J, Van der Vleuten C, Heeneman S. 2018. Stakes in the eye of the beholder: an international study of learners' perceptions within programmatic assessment. Med Educ. 52(6):654-663.

Schut S, Maggio L, Heeneman S, Van Tartwijk J, Van der Vleuten C, Driessen E. 2021. Where the rubber meets the road - an integrative review of programmatic assessment in health care professions education. Perspect Med Educ. 10(1):6-13.

Schut S, van Tartwijk J, Driessen E, van der Vleuten C, Heeneman S. 2020a. Understanding the influence of teacher-learner relationships on learners' assessment perception. Adv Health Sci Educ Theory Pract. 25(2):441-456.

Schut S, Heeneman S, Bierer B, Driessen E, Van Tartwijk J, Van Der Vleuten C. 2020b. Between trust and control: teachers' assessment conceptualisations within programmatic assessment. Med Educ. 54(6):528-537 
Schuwirth L, Valentine N, Dilena P. 2017. An application of programmatic assessment for learning (PAL) system for general practice training. GMS J Med Educ. 34(5):Doc56.

Schuwirth LWT, Van der Vleuten CPM. 2011. Programmatic assessment from assessment of learning to assessment for learning. Med Teach. 33(6):478-485.

Schuwirth LW, van der Vleuten CP. 2012. Programmatic assessment and Kane's validity perspective. Med Educ. 46(1):38-48.

Schneider J. 2014. Closing the gap... between the university and schoolhouse. Phi Delta Kappan. 96(1):30-35.

Sherbino J, Bandiera G, Doyle K, Frank JR, Holroyd BR, Jones G, Norum J, Snider C, Magee K. 2020. The competency-based medical education evolution of Canadian emergency medicine specialist training. CJEM. 22(1):95-102.

Teunissen PW, Bok HG. 2013. Believing is seeing: how people's beliefs influence goals, emotions and behaviour. Med Educ. 47(11):1064-1072.

Torre DM, Schuwirth LWT, Van der Vleuten CPM. 2020. Theoretical considerations on programmatic assessment. Med Teach. 42(2):213-220.
Van Der Vleuten C, Schuwirth L. 2005. Assessing professional competence: from methods to programmes. Med Educ. 39(3): 309-317.

Van Der Vleuten CP, Schuwirth LW, Driessen EW, Dijkstra J, Tigelaar D, Baartman LK, Van Tartwijk J. 2012. A model for programmatic assessment fit for purpose. Med Teach. 34(3):205-214.

Van Der Vleuten C, Heeneman S, Schut S. 2019. Programmatic assessment: an avenue to a different assessment culture. In: Yudkowsky $\mathrm{R}$, Soo Park $\mathrm{Y}$, Downing $\mathrm{S}$, editors. Assessment in health professions education. New York (NY): Routledge.

Van Der Vleuten CPM, Schuwirth LWT, Driessen EW, Govaerts MJB, Heeneman S. 2015. Twelve Tips for programmatic assessment. Med Teach. 37(7):641-646.

Watling C, Ginsburg S, LaDonna K, Lingard L, Field E. 2021. Going against the grain: an exploration of agency in medical learning. Med Educ. DOI:10.1111/medu.14532.

Wilson M, Sloane K. 2000. From principles to practice: an embedded assessment system. Appl Meas Educ. 13(2):181-208. 